\title{
Construction of Ecological Mode of College English Teaching under the Internet Plus Background
}

\author{
Ren Lingling \\ School of Foreign Languages, Henan University of Chinese Medicine, Zhengzhou, Henan, China
}

\begin{abstract}
The modernization of industry is inseparable from the development of English teaching. Under the background of "Internet plus", constructing an ecological mode of College English teaching has become an effective way to promote the reform of College English teaching. Based on the analysis of the imbalance of the function of the Internet plus teaching structure, the imbalance between the coordination functions of the ecological subjects, the imbalance between the ecological subjects and the Internet information technology, this paper puts forward the concept of improving the information literacy of the teaching subject and innovating the "teaching and learning". This paper expounds the idea of creating a network ecological teaching environment and giving full play to teachers' guiding role. At the same time, this paper constructs a multi-dimensional interactive ecological classroom, harmonious teacher-student relationship and other specific strategies to build an ecological model of College English teaching, in order to play the role of ecological subject and improve the effect of College English teaching.
\end{abstract}

Keywords: English teaching, ecological mode, teaching reform, industry, Internet plus.

\section{Introduction}

As one of the most important basic courses in Colleges and universities, College English has always been concerned. Especially in today's increasingly integrated world, English has become the key to international and global integration [1-2]. However, College English teaching, which is endowed with high expectations, has repeatedly fallen into the dilemma of time-consuming and low efficiency. After experiencing the pain of "deaf mute English", English education has been reformed in many aspects. It has not only greatly increased the proportion of listening questions in CET-4 and CET-6, added 13 language tests, and gradually opened oral English classes for non English majors, but also carried out the discussion and Research on English teaching mode with unprecedented breadth and depth [3].

\section{The reform and development of foreign language teaching mode}

In the past century, the vigorous development of linguistics, psychology, philosophy and other research fields has brought opportunities for the development of pedagogy, and also provided a brand-new perspective for the exploration of foreign language teaching mode. Behaviorism teaching mode, cognitive teaching mode and constructivism teaching mode were born one after another.

(1) Behaviorism teaching mode

The behaviorism theory put forward by American psychologists Watson and Thorndike at the beginning of the 20th century has a great influence on the fields of psychology and pedagogy. Behaviorism learning theory is also known as stimulus response theory [4-5]. Behaviorists believe that learning is the connection between stimulation and reaction, while teaching is to give students language stimulation and strengthen it positively, so as to further consolidate new knowledge. Behaviorism has given birth to three teaching models which have been widely used in foreign language teaching: grammar translation method, direct method and listening and speaking method. Byrne, an applied linguist, refers to grammar translation as PPP teaching mode, namely presentation, practice and production. Grammar translation, which has dominated foreign language teaching for nearly 200 years, attaches 
great importance to the study of grammar and vocabulary, which helps to lay a solid foundation for students' language learning [6]. However, its neglect of oral English teaching hinders the cultivation of students' listening and speaking ability. At the same time, the teacher led classroom teaching mode is not conducive to stimulate students' learning initiative and enthusiasm.Ecologization should be the highest realm of human survival, and the ultimate trend of world cultural development must be the ecological development of culture. The comparison between self-learning and traditional learning mode is shown in Table 1.

Table 1. Comparison between traditional teaching and Online Autonomous Learning

\begin{tabular}{|l|l|}
\hline Traditional teaching & Network autonomous learning \\
\hline Teacher's role as "actor" teacher & Acting teachers \\
\hline Students as passive receivers & Active learners \\
\hline $\begin{array}{l}\text { Teaching method blackboard + teacher }+ \\
\text { Classroom Activity }\end{array}$ & $\begin{array}{l}\text { Network multimedia Autonomous Learning }+ \\
\text { teachers + Classroom Activities }\end{array}$ \\
\hline $\begin{array}{l}\text { Teaching form explanation }+ \text { practice }+ \\
\text { Multimedia Courseware }\end{array}$ & $\begin{array}{l}\text { Classroom + online and offline learning + student } \\
\text { teacher collaboration }\end{array}$ \\
\hline $\begin{array}{l}\text { Teaching evaluation test }+ \text { question }+ \text { homework } \\
\text { Formative assessment }\end{array}$ \\
\hline $\begin{array}{l}\text { Teachers' quality, basic teaching skills and } \\
\text { teaching design }\end{array}$ & $\begin{array}{l}\text { Network comprehensive knowledge } \\
\text { integration ability }\end{array}$ \\
\hline The ultimate goal is to gain knowledge & Get knowledge + learn to apply knowledge \\
\hline
\end{tabular}

The direct teaching method was proposed by French teacher Jean Gunn at the end of the 19th century, but Belize and Palmer are responsible for raising it to the theoretical level and making it the mainstream teaching mode of foreign language teaching. The direct method attaches great importance to oral English teaching, which is conducive to the cultivation of students' oral communication ability, especially for junior learners. However, it overemphasizes the intuition of teaching and ignores grammar teaching, which is not conducive to students' systematic mastery of the target language system and increases the difficulty of deep learning of the target language [7-9].

The listening and speaking method originated from the army method used in the rapid cultivation of foreign language talents during World War II. Listening and speaking advocate "listening and speaking first, reading and writing to keep up", pay attention to a lot of practice, believe in "repeated practice, form a habit" teaching concept. Therefore, in the process of teaching, teachers usually organize teaching with sentence patterns as the key link. First of all, the new sentence patterns are mechanically repeated, and on the basis of students' proficiency, the replacement training is carried out, so as to strengthen the understanding of the new sentence patterns and finally achieve the degree of flexible use. This kind of teaching mode pays attention to the practicality, interest and authenticity of foreign language learning, which can still be used for reference in today's foreign language teaching, but the simple sentence pattern practice often ignores the cultural factors, so that students can not contact with the essence of the language.Self-learning model base on Agent network is shown in Figure 1. 


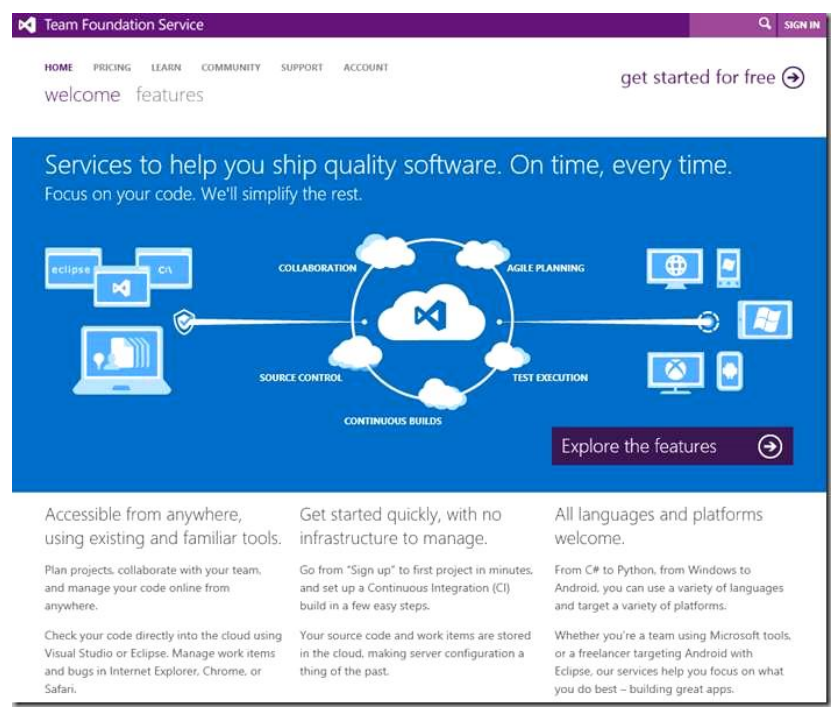

Figure 1 Self-learning model base on Agent network

\section{(2) Cognitive English teaching model}

The linguistic basis of cognitive approach is transformational generative grammar proposed by Noam Chomsky, a famous American linguist. According to the transformational generative approach, language is a system governed by laws, and language learning is a process in which people use language creatively Cognitivists believe that learning is not a passive process of stimulus response, but an active process of learners' efforts to acquire knowledge. Therefore, learners should be active participants in the learning process rather than passive receivers of reinforcement and practice [10]. Cognitive approach advocates the teaching concept of student-centered and allround development of listening, speaking, reading and writing. This is conducive to stimulate students' interest in learning and concentration, and develop their intelligence factors. However, the cognitive approach overemphasizes that teaching should be based on the understanding of grammar rules, which is not in line with the law of language learning and is not conducive to the cultivation of students' listening and speaking ability.

Not only the target language culture should be the teaching content, but also the learner's own culture should be an important content in teaching8. Therefore, in addition to the vocabulary required to master in the textbook, the author requires students to extract and refer to the common vocabulary in reading, find out the meaning, and establish a personal Vocabulary Manual (see Table 2).

Table 2. Vocabulary manual table

\begin{tabular}{|c|c|}
\hline Words or phrases & 0.4 \\
\hline Meaning & 0.4 \\
\hline Example sentence & 0.4 \\
\hline
\end{tabular}

(3) Constructivist English teaching model

Constructivists believe that knowledge is not simply transferred from teachers to students, but a process of meaning construction. Students are not passive receivers of tape recorders, but active constructors of knowledge. Constructivism has produced communicative approach and task-based approach. The English linguist Wilkins published the national syllables in 1976, which is of guiding significance to the communicative approach. Communicative approach emphasizes learning English in English and opposes the use of mother tongue in foreign language classroom, which makes the focus of teaching shift from the form of traditional grammar translation 
method to the content. However, due to the excessive pursuit of the purpose of language communication, the training of students' reading and writing ability is not enough, and the mastery of basic language knowledge is also lacking.

Task based teaching method is the development of communicative teaching method. It takes real life scene as the teaching center, and requires students to combine in class learning with out of class learning, through exploring autonomous learning.

Willis put forward the PTP model of Task-based Teaching in 1996: the pre task stage in which teachers guide and assign tasks; Students use their knowledge to complete the task cycle; The post task of explanation and practice. In the task-based teaching mode, students acquire language by learning real language materials and using their grammar knowledge, which helps to improve their ability to solve practical problems. But for the students with poor learning initiative and weak sense of participating in the task, the effect of task-based teaching mode is not easy to show. Each change of teaching mode has promoted the development of language teaching to some extent. However, the three teaching modes that once had a significant impact on foreign language teaching have not been freed from the shackles of the traditional thinking pattern of language teaching: either one-sided emphasis on learners' initiative and initiative, or excessive attention to the decisive external factors, Instead of regarding each subject and environment in language teaching as an ecological factor in the same ecosystem, it is difficult to find a sustainable language teaching method from the perspective of the whole and development.

\section{The connotation of the teaching mode of ecological language}

The rapid development and fruitful ecology provides a new perspective for the research of other fields. The basic ecological point of view is applied to the field of SLA, which has a great influence on the change of foreign language teaching mode. The ecological language teaching concept is formed by the combination of ecological theory and social culture theory by western scholars in recent years. Social culture theory is developed by a famous psychologist in the Soviet Union, on the basis of absorbing the thoughts and theories of other psychologists and educators in the world. Its core contents include intermediary, regulation, internalization and recent development zone. Social culture theory integrates social environment factors into learning system, which is not only the source of language input, but also the basis of cognitive ability development.

This new perspective has opened a new platform for foreign language teaching research. But because of the early death of vygowski, some of the social and cultural theories were advanced by his students and colleagues along his thoughts. So, up to now, the theory of social culture is still an open theory to be improved. In the 21 st century, vanlier combines ecolinguistics with social culture theory and applies it to language teaching creatively. It expounds the relationship and function of language, social environment, teachers and learners in foreign language learning from multiple perspectives, and regards foreign language teaching as an organic ecological whole. The experimental data are shown in Table 3.

Table 3. The scores of English autonomous learning ability and the average of each category after the experiment

\begin{tabular}{|l|l|l|l|l|}
\hline Total score & $\begin{array}{l}\text { Learning } \\
\text { motivation }\end{array}$ & Goal setting & Learning strategy & Cognitive ability \\
\hline 64.65 & 2.48 & 2.76 & 2.37 & 2.68 \\
\hline 47.33 & 2.46 & 2.73 & 2.26 & 2.42 \\
\hline
\end{tabular}

The ecological language teaching mode creatively uses the emergence theory, and holds that the language learning and language application are complex dynamic processes of various elements appearing at all levels. The development of language also emerges in the interaction between the subject and the environment in which the 
language acts. The ecological language teaching mode also studies language learning from the perspective of time and space, and finds that language learning also shows remarkable rheological characteristics in time and space. Language acquisition is the result of the multi-dimensional change of learning time and space. The ecological language teaching mode at the same time expounds the relationship between learning subject and learning environment by means of Fu burden. It is believed that in the teaching process, the language taught by teachers in Fuxing only provides a potential acquisition possibility for learners. Students can realize language acquisition only after continuous practice and repeated application. The concept of "Fu" is a psychological concept, which refers to the relationship between biology and environment in the ecosystem. In 2000, the concept was applied to the study of SLA by ecological linguist Leo van Riel, and then second language acquisition was studied as an ecological phenomenon. The correspondence in the teaching of ecological language refers to the relationship between learners or teachers and the environment that provides opportunities for or prevents their actions. Therefore, the ecological language teaching mode is a kind of integrated, systematic and ecological language teaching mode which takes into account learners, teachers, languages and environment.

From the perspective of ecological language teaching, College English classroom is also a micro ecosystem. All the components interact and work together to maintain the stability and development of College English teaching.

\section{(1) The ecological roles of teachers and learners}

Foreign language teaching is a system, which can be studied with the method of system theory. However, in addition to the theory of system theory, we should also treat and deal with the problems in the process of teaching from the perspective of ecology, because foreign language teaching system is actually an ecosystem. The ecological environment of College English classroom is equivalent to the non biological environment in the ecosystem. As the main body of the classroom, teachers and learners are equivalent to producers, consumers and decomposers in the ecosystem. They are a high unity of the three. First of all, a teacher is a decomposer. He should be good at reasonably decomposing and processing the knowledge system so that students can better grasp it; Teachers impart knowledge to students by means of textbooks, language and environment. As far as students are concerned, teachers are producers of knowledge; At the same time, according to the principle of "mutual benefit between teaching and learning", teachers are constantly promoting their professional development in the process of lesson preparation and teaching, so teachers are also consumers of knowledge. Students get new knowledge from teachers. They are the main consumers of knowledge; But in the process of acquiring knowledge, learners will decompose the new knowledge consciously or unconsciously, and then internalize it into a part of their own knowledge system. According to constructivism theory, students' mastery of knowledge is essentially the process of their own construction of knowledge, so learners are also producers of knowledge.

\section{(2) The ecological significance of language and environment}

Ecological language teaching mode is comprehensive and dynamic, and its dynamic nature is reflected in the temporal and spatial variability of students' language learning. The current mode of language learning is usually the reproduction and transformation of the previous mode of mother tongue learning; At the same time, the accumulated experience and formed thinking in the process of language learning will actively construct their own learning schema, which will have an impact on the current and future linguistic learning. Language learning is promoted in the process of experience inheritance and transformation, so it is a dynamic process of keeping pace with the times. Language learning environment mainly refers to international environment, family environment and classroom environment. In today's global integration, English has become the Esperanto, and mastering English is the necessary quality to become a future citizen of the earth. This consensus has become a powerful driving force to promote English learning. At the same time, China's education authorities also attach great importance to English learning, not only popularize English education in primary and secondary schools, but also actively improve English teaching equipment and optimize the classroom environment. All these make Chinese parents pay unprecedented attention to English learning, and the investment in children's English education is increasing year 
by year. This kind of good atmosphere creates a virtuous circle of ecological environment, which greatly promotes English teaching.

\section{The construction of ecological model of College English Teaching}

Language is not a simple import and output. It is also a dynamic and developing system. It is a cognitive marker to acquire meaning and engage in meaningful teaching activities with the participation of teachers and students Therefore, language teaching classroom can be regarded as an ecosystem, a complex and changeable system. However, throughout today's College English classroom, ecological imbalance can be found everywhere. Teachers hold old teaching materials and repeat the teaching plan of several years ago; The students are absent-minded Therefore, only by choosing appropriate teaching contents and methods can we build a healthy and harmonious college English teaching ecological model.

(1) How to choose ecological English teaching content

Ecological language teaching emphasizes the harmony of learners, teachers, language and environment as well as the development of students. In College English teaching, we should not only pay attention to the balanced development of students' listening, speaking, reading, writing and translation ability, but also constantly update the teaching content with the times. Language is not immutable, it must change with the development of society. Some textbooks have been compiled for a long time, and some contents marked with the brand of the times are obviously not suitable for the current language learning, so we should resolutely abandon them. English curriculum should choose the blueprint that is in line with the language norms of the times, and choose the teaching content that is meaningful for the survival of the future society. At the same time, the teaching content under the ecological mode of College English teaching should not only be limited to the teaching of language knowledge, but also be widely involved in western culture. Because language ecology also includes the ecological use, that is, the healthy and harmonious use of language. Learning the same cultural knowledge can improve the appropriateness of students' English expression. The ecological classroom of foreign language teaching should be a cultural castle. Based on Ecological linguistics and combined with the concept of ecological education, foreign language learning should be transformed from the acquisition of a set of symbol system into a constantly developing ecosystem full of vitality with the integration of language and culture.

\section{(2) Choosing ecological English teaching methods}

The ecological mode of College English teaching has the characteristics of diversification and flexibility in the selection of teaching methods. As long as it can promote the acquisition of students' language knowledge, the improvement of cultural literacy and the all-round development of people, the teaching methods can be used in classroom teaching. The ecological College English classroom also requires teachers to change the traditional education concept, abandon the "Teacher centered" teaching behavior, and regard students as equal ecological factors, the main producers of knowledge and the center of all teaching activities under the guidance of the dynamic and sustainable ecological teaching concept. Teaching should start from the actual situation of students, and aim at cultivating their initiative, independence and creativity. This requires teachers to design classroom activities, create situations, highlight students' subjectivity and improve their self-development ability. Language learning, especially cultural perception, is far from enough to rely on classroom teaching in non source language environment. Some teachers complain that foreign languages are difficult to teach, which is largely because we try to teach in class rather than help students learn out of class.

The contemporary language learning environment has been greatly improved by the development of multimedia equipment, and the time and space for English learning have become infinitely broad. Teachers should encourage students to make good use of electronic resources to learn as much as possible about the unique Western culture and values by listening to English news, learning to sing English songs and watching English movies, so as to 
make English learning move from a small classroom environment to a large social classroom. This is conducive to creating a good language learning environment, so that students can learn a foreign language in the real language situation and feel the culture. At the same time, the rapid development of MOOCS since 2019 also provides a way to improve college English teaching methods. Teachers can follow the "MOOCS" model and combine their own teaching videos, excellent micro lesson works and demonstration teaching videos to make online teaching videos that combine short videos with customs clearance quiz, and take online videos as the online link of teaching. Students are required to "listen to lectures" outside the classroom, while in the classroom, they focus on in-depth sharing, discussing and solving problems. This kind of "flipped classroom" mode helps to promote the change of teachers' role from a simple lecturer to an enlightener and motivator of learning. At the same time, it also makes up for the lack of "student student communication" and "teacher-student interaction" in pure "MOOC" teaching.

\section{Conclusion}

The ecological College English classroom is a system full of vigor and vitality, which completely subverts the behaviorism teaching mode centered on "teaching" with respect for students' autonomy and creative stimulation. Although the teaching mode of cognitivism and constructivism also advocates taking students as the center, it separates learners from the learning environment and ignores the cultivation of students' Socialized subjectivity and their all-round development as human beings. In view of this, we should break away from the dualism, integrate behaviorism, cognitivism, constructivism and social culture theory, and learn from the fruitful achievements of ecology to construct the ecological teaching mode of College English.

\section{References}

[1] Duxi. The One Hand, the "one Belt, One Road" Strategy, the Analysis and Training Strategy of Intercultural Communication Ability of College Students. Journal of Jilin Radio and Tv University, 2019, 000 (009): 135-136.

[2] Tao Hong. Construction and Cultivation of Contemporary College Students' Intercultural Communicative Competence. Management and Technology of Small and Medium Sized Enterprises, 2019 (22)

[3] Han Juhong. Cultivation of College Students' Intercultural Communicative Competence Based on "experience Philosophy". Journal of Xinxiang University: Social Science Edition, 2012 (04): 183-185

[4] Wang Jijun, Xiu Yongfu. Experimental Research on the Cultivation of College Students' Intercultural Communicative Competence by Mobile Learning. Audio Visual Education Research, 2014, 035 (009): 47-52

[5] Li Hua, Li Bin. A Cognitive Approach to Improve the Intercultural Communicative Competence of Non English Majors. Journal of Changchun University of Technology, 2013 (1): 196-197 + 233

[6] Xie Meirong. Cultivation of Intercultural Communicative Competence of Non English Majors. Educational Theory and Practice, 2006 (12): 59-61

[7] Xie Meirong. On the Cultivation of Intercultural Communicative Competence of Non English Majors. Educational Theory and Practice, 2006

[8] Wang Xiaoyan. Intercultural Communication and the Cultivation of College Students' Intercultural Communicative Competence. Journal of Hohai University: Philosophy and Social Sciences Edition, 2011 (01): 85-88

[9] Zhong Hua, Fan Weiwei. a Theoretical Framework for the Construction of Intercultural Communicative Competence of Chinese College Students. China Foreign Language Education, 2013, 000 (003): 19-28

[10] Liu Baining. Cultural Teaching and the Cultivation of College Students' Intercultural Communicative Competence. Educational Exploration, 2007 (06): 33-34 